\title{
Optimal Parameter Updating in Assisted History Matching Using Streamlines as a Guide
}

\author{
A. Kazemi* and K.D. Stephen \\ Institute of Petroleum Engineering, Heriot-Watt University, Edinburgh, Scotland, EH14 4AS - United Kingdom \\ e-mail: alireza.kazemi@pet.hw.ac.uk -karl.stephen@pet.hw.ac.uk \\ * Corresponding author
}

Résumé - Mise à jour optimale des paramètres dans un processus de calage d'historique en s'aidant des lignes de courants - L'utilisation de méthodes de calage d'historique assisté est de plus en plus fréquente pour déterminer différentes combinaisons de modèles de réservoir reproduisant les données de production. Les modèles comprenant un grand nombre de cellules contiennent des millions de paramètres inconnus, et leur attribuer des valeurs appropriées peut s'avérer difficile. En pratique, tous les paramètres n'ont pas la même importance, et identifier les zones du réservoir où les paramètres doivent être mis à jour est un défi. Dans cette étude, nous étudions les méthodes de calage d'historique en nous concentrant sur les sous-ensembles des paramètres du modèle, et nous utilisons les lignes de courant pour choisir les zones du modèle qui doivent être modifiées. Nous identifions les régions du réservoir affectant des puits particuliers et nous y ajustons les propriétés du réservoir (fraction de roche réservoir et perméabilité). Les changements sont réalisés à partir de la méthode des points pilotes associée à un algorithme d'optimisation par voisinage.

Nous appliquons cette méthodologie au champ Nelson (North Sea, UK) pour lequel les prévisions de production dépendent de l'incertitude sur la distribution des argiles. Le champ est divisé en régions sur la base des performances des plus mauvaises prédictions aux puits. Nous forçons les modèles de réservoir à respecter les historiques de production pour améliorer les taux de production. Les régions nécessitant des changements sont suffisamment distinctes pour que nous puissions les modifier une à la fois. Nous comparons également nos résultats à une approche plus $a d$ hoc qui implique la modification de toute la zone autour du puits. Nous observons que, pour les puits d'intérêt, l'approche guidée par les lignes de courant amène à une amélioration de $70 \%$ du calage des données de production comparé au modèle de départ et à une réduction d'environ $40 \%$ des écarts pour les prévisions. Cette amélioration est deux fois plus élevée que celle apportée par une modification des propriétés tout autour du puits.

\begin{abstract}
Optimal Parameter Updating in Assisted History Matching Using Streamlines as a Guide - It is becoming more and more common to use assisted history matching methods to find different combinations of reservoir simulation models that agree with production data. Models with a large number of cells contain millions of unknown parameters and selecting the correct property values can be difficult. In practice, not all are important but finding which parts of the reservoir require updating is a challenge. In this work, we investigate methods of history matching by focusing on sub-sets of the full array model parameters and we use streamlines to help us choose where the model requires change. We identify localities in the reservoir that affect particular wells and we update reservoir properties (net:gross and permeability) within. We control changes using the pilot point method combined with a Neighbourhood Algorithm.
\end{abstract}

We apply these approaches to the Nelson field (North Sea, UK) where uncertainty of the shale distribution controls predictions. The field is divided into localities based on the performance of the worst 
well predictions. We history match to improve production rates. The localities that require change are sufficiently separate that we can modify them one at a time. We also compare our result with a more ad hoc approach where the whole area around the well is modified. We find that, for the wells of interest, the streamline guided approach gives a 70\% improvement in the history match from our starting model and around $40 \%$ reduction of misfit in prediction. This improvement is twice that of modifying the properties all around the well.

\section{Nomenclature}

$Q \quad$ Production rate, water or oil ( $\mathrm{m}^{3} /$ day)

$O B S$ Observed production data

CAL Calculated production data

$\sigma_{Q} \quad$ Standard deviation of observed data ( $\mathrm{m}^{3} /$ day)

$n_{i} \quad$ The initial sample NA needs for its initialisation

$n_{s} \quad$ Total number of models NA generate for each new step

$n_{r} \quad$ The best model chosed after each step of NA for generation of Voronei cells

\section{INTRODUCTION}

History matching is an inverse problem where the aim is to find a set of best reservoir parameters such that simulations can honour the real observations of the reservoir such as well pressure, oil, water and gas rates or time-lapse seismic signatures. This process involves identification and selection of uncertain reservoir parameters which are modified to be consistent with geological information. Simulations are run using updated parameters and the output is compared with observed data through an objective function. Further modifications are then made and the process is repeated until a good match to history is obtained. Due to the number of parameters involved and the limitation of data which leads to nonuniqueness of solutions, this process is a time consuming and tedious task.

Over the last four decades or so, researchers have tried to improve the efficiency of the process by automatically minimizing the objective function using different various algorithms deterministically (Watson and Lee, 1986; Tan, 1995; Bissell et al., 1997; Zhang et al., 2005) or stochastically (Ouenes et al., 1993; Portelland and Prais, 1999; Walker et al., 2008). Additionally, researchers have focused more on honouring the geostatistical constraint of the model when updating the reservoir parameters by using parameterisation methods like pilot points with Kriging (De Marsily et al., 1984), the gradual deformation method (Hu, 2001), probability perturbation (Caers, 2003) and by encorporating geostatistical methods within the Ensemble Kalman Filter (Haugen et al., 2006; Evensen et al., 2007). For some, the aim has been to use assisted tools to find the main locations and properties of the reservoir which need updating by using streamline concepts (Baker, 2001; Agarwal and Blunt, 2004; Maschio and Schiozer, 2005) or other measures of sensitivity such as the adjoint approach (Chen et al., 1974; Chavent et al., 1975).
Additional approaches have used streamlines with various parameterization schemes (Le Ravalec-Dupin and Fenwick, 2002; Hoffman and Caers, 2005; Fenwick et al., 2005; Gervais and Roggero, 2010; Le Ravalec-Dupin, 2010). These approaches are more reliable compared to the ad hoc methods used for choosing the reservoir regions to be updated such as the region around the wells (Solorzano et al., 1973). Various improvements can be made to each part of Automatic History Matching (AHM) loop and which may lead to better predictions with greater efficiency. Because of the complexity of the reservoirs, however, research continues to makes this process accessible in general.

In this study, we perform Automatic History Matching (AHM) of production data on a North Sea field using the Neighbourhood Algorithm (NA) (Sambridge, 1999) as the optimization tool and we combine that with a parameterization scheme based on pilot points with Kriging in order to honor the geostatistical distribution of properties in the reservoir. Further, we use streamline simulation (Schlumberger, 2011) as a guide to help us choose the regions of the reservoir that are important for updating. We also introduce a suitable parameter updating scheme which dramatically reduces the number of parameters we need to change during the automatic inversion stage and this is very important as it helps to reduce the number of simulation runs with significant savings on CPU time.

First, we introduce the streamline based selection approach and the parameterization scheme used in AHM in the method section and then, we apply this workflow on the Nelson field. At the end, we compare results for this approach with a more ad hoc method where we update the reservoir in the vicinity of production wells. This study shows that optimal parameterization with the help of streamlines gives a better result to match the history of the wells and, further, we also get a good forecast.

\section{METHOD}

\subsection{History Matching Workflow}

Our history matching method is based on an automatic workflow presented in Figure 1 where we start with a base model supplied by the operator of the field around which we generate new models as perturbations. First we need to define areas in the reservoir which need improvement (we discuss this in the next section). Then in each area, we use the pilot point method with Kriging (De Marsily et al., 1984), also known 


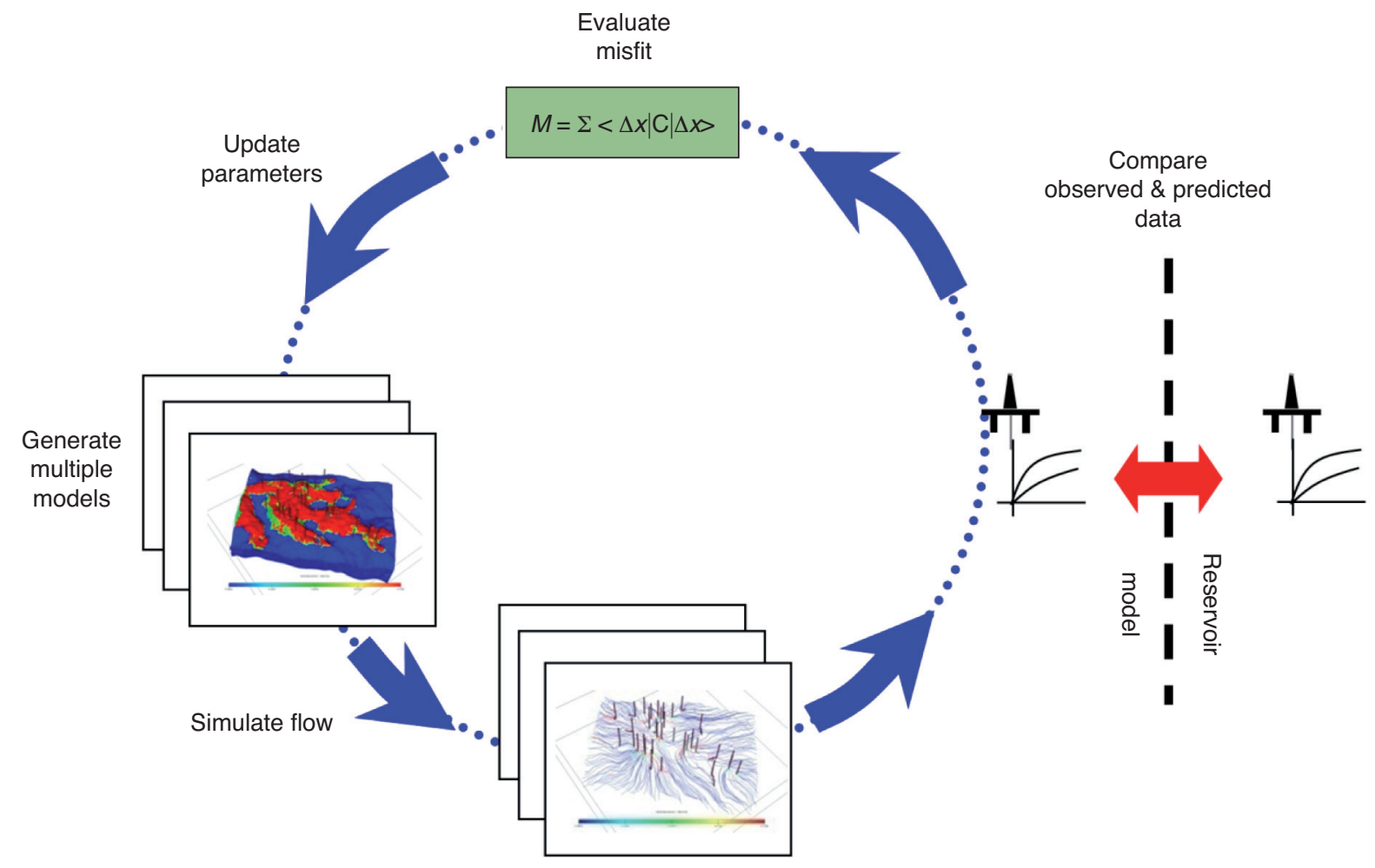

Figure 1

The automatic history matching workflow (details in Stephen et al., 2006, 2009).

as the master point method (Gomez-Hernandez et al., 1997) to control updates. Pilot points are used to directly set where changes are made to properties such as permeability and net:gross. The change at the pilot point becomes the parameter of the inversion scheme. These changes are interpolated laterally using Kriging. The changes are applied uniformly in the vertical direction. In general, we may choose to include vertical correlation in the Kriging process. Of course, this may require introduction of additional pilot points and to avoid this we have assumed an infinite vertical correlation length within the interval. Apart from that, the vertical correlation length must be obtained. Variations to properties (permeability and net:gross) most likely reflect variations in amalgamation (e.g. Stephen et al., 2001) and we could obtain the vertical correlation data from outcrops or by inspection of well data. In order to reduce the number of unknowns and to spread changes more smoothly, a set of pilot points may be grouped so that the same changes are applied to each point in the group. This has the effect of creating a region of change. It is a compromise between boxes of change that engineers have used traditionally (e.g. Gradzones, Bissel et al., 1994) and pilot points with long correlations which can induce very strong local changes in a few grid cells.
Modifications at the pilot points are initially chosen randomly and a number of new models are generated. We simulate each model by using streamlines which is appropriate for the field we are studying. In other fields, finite difference simulation may be required although streamline information may still be obtained. We compare predicted production data with the observed data using an objective function:

$$
\text { Misfit }=\sum \frac{\left(Q^{O B S}-Q^{C A L}\right)^{2}}{\sigma_{Q}^{2}}
$$

At the end of the loop, we use the Neighborhood Algorithm (NA) as a stochastic quasi-global optimization algorithm to select new parameter values automatically. We then iterate through the loop until the objective function is minimised sufficiently.

The NA is a stochastic iterative sampling algorithm introduced by Sambridge (1999) originally for earthquake seismology. The process is initialized by generating $n_{i}$ models using quasi- or pseudo-random methods (as menthioned above). In each iteration that follows, the best $n_{r}$ models are selected from all models generated so far using the misfit in Equation (1). The neighbourhoods of the models in the parameter space are identified by construction of Voronoi cells. 
Then, $n_{s}$ new models are generated such that $n_{s}: n_{r}$ models are randomly sampled from the neighbourhoods of the each of the best $n_{r}$ models. That is, the neighbourhoods represent a refined sample volume in the parameter space within which uniform random sampling is performed. Ultimately, as each iteration progresses, neighbourhoods are recomputed and the sample volume of the parameter space becomes smaller and smaller and the sample density will follow the probability density of the parameters (Sambridge, 1999). The parameters $n_{r}$ and the ratio $n_{s}: n_{r}$ can be tuned. Larger values of $n_{r}$ increase the exploration of the parameter space while large $n_{s}: n_{r}$ enable exploitation and speed up convergence.

One drawback of this algorithm is that for complex misfit surfaces, we require 2 nd models initially to properly separate out neighbourhoods (Sambridge, 1999). To overcome this difficulty, we introduce a parameter updating scheme in order to reduce the number of unknowns of the problem which drastically reduces the number of simulation runs. This approach will be discussed later in this paper.

Now, we have to determine where we should focus our attention for updating. These areas will have properties estimated with high uncertainty but also have an important effect on the misfit. We address this difficulty by using the streamline guide which will be discussed later in this section.

\subsection{Streamline Guide Concept}

In heterogeneous reservoirs, we often see the effect of preferential flow paths, which may be observed in simulators using streamlines. These will appear to be more densely distributed in regions of high flow rate (Fig. 2). In fields under water flood, they are set up by a combination of the orientation of producer wells relative to the source of any water supply which may come from injectors or an aquifer. The geological architecture of the field may also control this behaviour. Since these regions channel most of the flow and particularly affect the arrival time and subsequent production of water, it is reasonable therefore that we should focus on them first to improve the forecast from models, particularly in cases where there is a large difference between predicted and observed production rates. This will help reduce the number of parameters used to change the properties of the model. Therefore, we add pilot points as shown in Figure 2.

Then, we need to consider what kind of changes we need to make in these regions. It may be that the permeability of such the high flowing regions may be greater or lesser in comparison to the surrounding area or the width of such regions may be incorrect in the model. Early breakthrough will tell us that the channelization is too strong and vice versa. Channelization may be reduced by decreasing high permeability or increasing low permeability for example. Therefore, we apply our initial modifications to the model on these regions of high flow and allow permeability to increase or decrease. We assume that the simulation model is a reasonable representation of the dominant flow pathways in the reservoir and for the purpose of this work, they will not change significantly with additional realizations or changes to the geological model. This is reasonable in many cases where the model is constrained to seismic data at the larger scale and the flow pathways are dominated by the orientation of wells relative to injectors and the aquifer. Figure 2 also shows that there are changes in the streamline density over time. If this changes too much then we cannot focus on one area. On the other hand, we aim to use the most representative distribution to identify the region we wish to update. We calculate the misfit as a function of time and focus on time steps where the misfit is largest. More details are given below.

In previous studies (Cheng et al., 2004), the impact of streamline sensitivity from changes to individual cells was considered. In our case, we consider a general volume through which a cluster of streamlines passed. We hope to generate a more qualitative understanding therefore. This also allows us to set up a pilot point group in an appropriate location.

\subsection{Local Multi-Variable Approach}

All history matching methods require a scheme to search the parameter space using information about misfits from existing

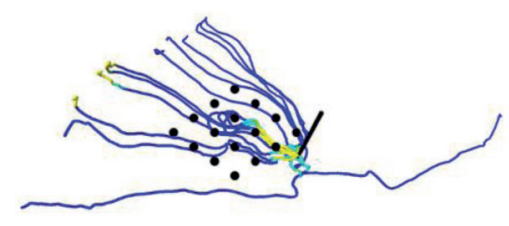

a)

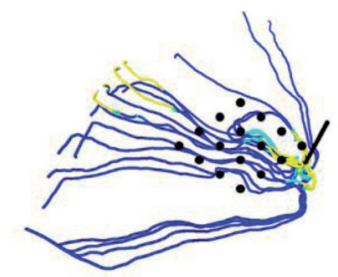

b)

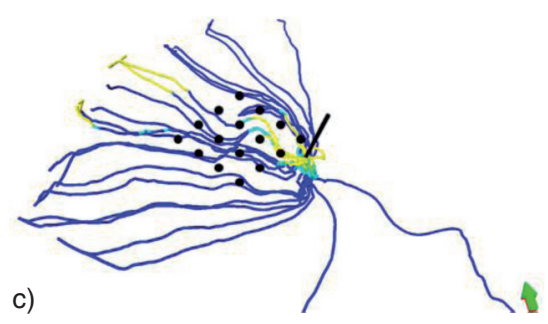

Figure 2

The distribution of streamlines aroud an example well over three time steps that are separated by three months. The dots indicate the location of pilot points that were applied for this well. 


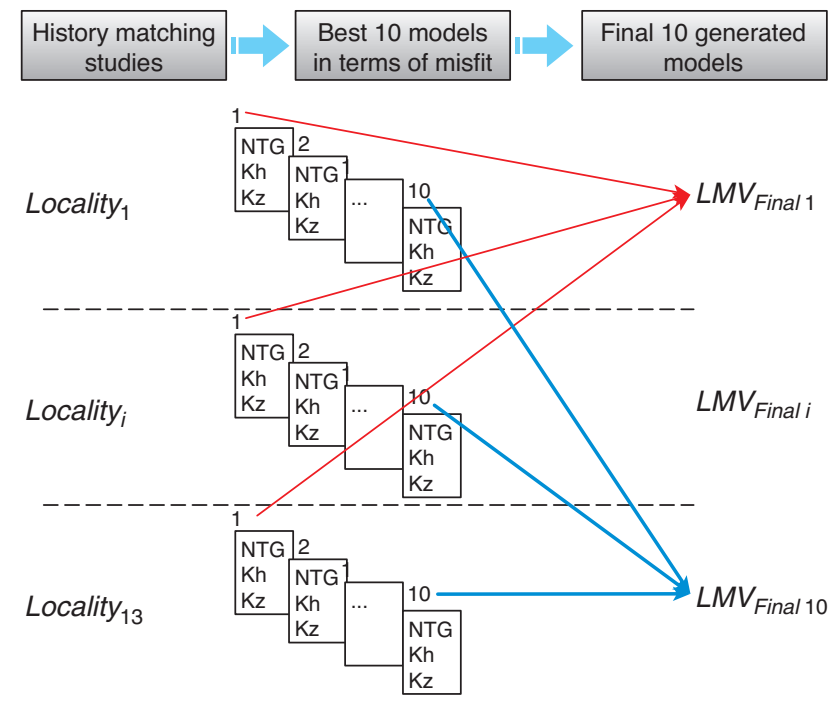

Figure 3

The Local Multi-Variable (LMV) approach for parameterization of the reservoir in automatic history matching. Arrows indicate the combination of parameters for the final model. $\mathrm{LMV}_{\text {Final } 1}$ consists of the parameters that gave the lowest misfit for the wells at each of the localities and so on.

models. In general, we may have to assume that each parameter that we change interacts with the others when considering their effect on the misfit. In large dimensional problems, this assumption can require that a prohibitively large number of simulations be carried out. In this work, we investigate the parameter interactions heuristically to determine whether we can search the parameter space in a more efficient manner.

We use an approach called "local multi-variable" (Kazemi and Stephen, 2012) to reduce the required number of simulations where the variables net:gross, horizontal and vertical permeabilities are updated using pilot points in a geographically local manner (Kazemi and Stephen, 2009). We consider that parameters at every locality (i.e. variables at each pilot point) may interact with each other but not with others elsewhere. All parameters at each locality are updated and one locality is modified at a time (Fig. 3). A parameter range refinement step is considered if it appears that there is no convergence or the search is stuck on the limit set initially. After all localities are updated, the final results are amalgamated into a single model.

\section{APPLICATION}

\subsection{Nelson Field}

The Nelson field is an undersaturated oil field located in bocks 22/11, 22/6a and 22/12a in the UK Central North Sea. The first production was in 1994 and 27 production wells were drilled up to 2000. The original oil in place was estimated at 126 million cubic metres of oil and by the end of 2000, 47 million cubic metres had been produced from the field (UK DTI, 2009). The production drive is aquifer supported coupled with the water injection from 4 injection wells in the edge of the reservoir.

The reservoir sands in Nelson are turbidities with excellent reservoir quality with average net:gross of $70 \%$, average porosity of $23 \%$ and permeability ranging from 200 to 1700 millidarcys. Geologically, there are three distinct intervals in Nelson separated mainly by shale. Each interval has a channelized characterization. The porosity of the sands is consistent and obtained from seimic data whle the amount and distribution of shale within and between the channels are our main uncertainties. We use monthly volumes of water and oil produced to generate either monthly or biannual rates of production, the latter is used for fixing pressures in the streamline simulation approach that we use.

\subsection{History Matching of Nelson}

We set well controls using historical liquid rates to maintain the correct voidage and we specify a general limit for bottom hole pressure of the wells to make sure that the bubble point pressure is not reached, as observed. The misfit is calculated based on oil and water production rates. We history matched from 1994 to 2000 and we check the quality of the result by forecasting from 2000 to 2003. We allow permeability and net:gross to vary by an order of magnitude increase or decrease. Net:gross is obviously not allowed to exceed unity.

In this history matching study, we focus on updating regions around 13 of the worst matching wells in the base

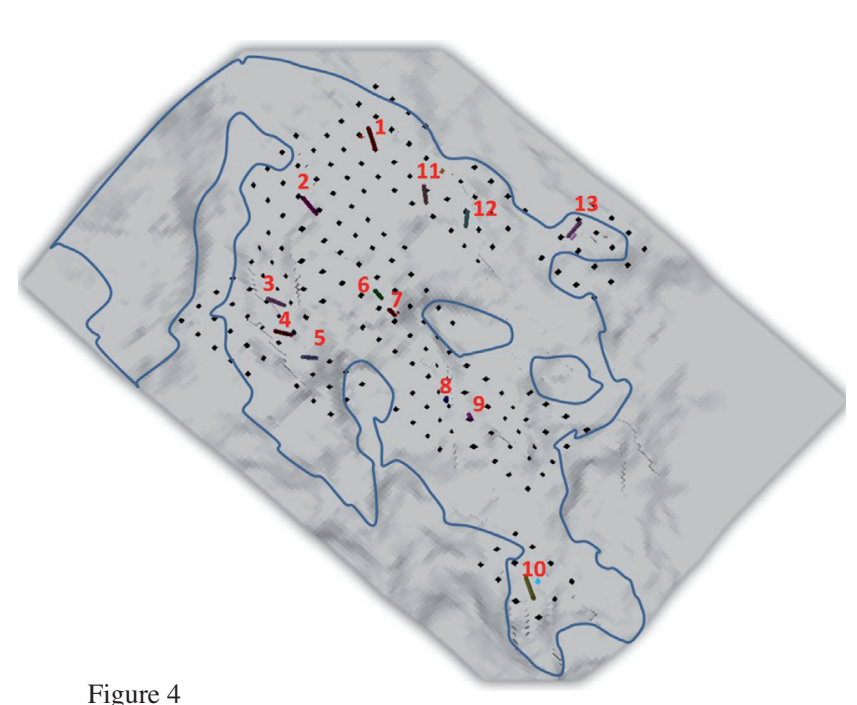

Location of wells selected for history matching. The coloured dots are representative of pilot points for each well. The solid line indicates the original oil water contact. 


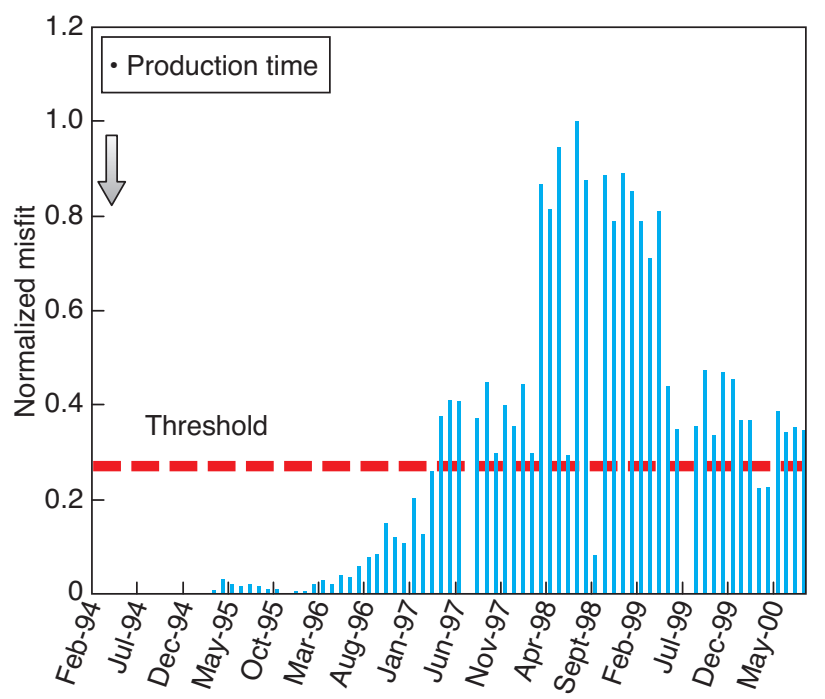

Figure 5

The normalized misfit value for an example well as it varies over time. A threshold of $25 \%$ of the maximum is used as a threshold for investigating streamline distributions.

case model (Fig. 4). We vary net:gross to account for the volumetric uncertainty of shales. Vertical permeability is changed to allow different degrees of connectivity of shale horizontally. Horizontal permeability is varied to capture or remove the impact of shale drapes. Porosity is kept constant because it is obtained from 3D seismic data. Seven wells are completed in the first geological interval only so for these localities and we only update the reservoir properties in that interval. For each of these wells, there are only 3 variables modified so each sub-problem is three dimensional. The other 6 wells that we focus on are completed in both intervals therefore we need to update properties in both geological intervals and each of them is a six dimensional problem. In total, there are now 57 dimensions to the parameter space. Each sub-problem is considered in turn. For localities that are three dimensional, we used 16 models initially and generate 10 new models per iteration of the NA. A total of 5 iterations are performed. For the six dimensional problems, 128 initial models are generated and 10 iterations are used within which 18 new models are generated. In all cases, 2 models per neighbourhood are generated in the parameter space (i.e. $\left.n_{s}: n_{r}=2\right)$.

To identify where to put the pilot point groups around the wells shown in Figure 4, we use the streamline based guide described above. For some wells, the misfit for each well varies over time (e.g. Fig. 5) and we now focus on those time steps with biggest misfit by assigning a suitable threshold of $75 \%$ of the maximum misfit. Then, the streamline density is considered and the regions containing most flow are targeted with pilot points.
In Figure 6, we see the streamlines that are used to distribute pilot points in Figure 4. Each pilot point region is allocated to one well according to high streamline density. We apply the same procedure to choose pilot point locations for other wells. If we increase the number of targeted wells, we should increase the number of pilot points and these will eventually overlap. The separation between pilot points is 5 simulation cells $(\sim 500 \mathrm{~m})$ in this study and for the cells around the pilot points Kriging with a variogram range of 15 cells $(\sim 1500 \mathrm{~m})$. Depending on the size of the area that is updated, the number of pilot points vary between 9 and 25 per group of pilot points.

We analyse the reduction of oil and water production misfits via history matching for each well in Figure 7. The reduction of total production misfit ranges from $82 \%$ to $95 \%$ over all of the wells which is very good. All parameters converge to a better value during updating. Note that a correct parameter range is required otherwise convergence may not occur.

After history matching, we select the 10 best parameter combinations from each pilot point location and combine them to generate a set of 10 best models overall. In Figure $8 \mathrm{a}, \mathrm{b}$ we show the total oil production rate and the field water cut for one of the best models. Compared to the base model, we get a significant improvement in matching the production profile of field oil rate and water cut.

To better understand how the reservoir parameters change as a result of history matching, we plot the ratio of best model parameters to the base case for each variable in Figure 9. On balance, we increase parameter values in the model although there are regions where decreases are necessary.

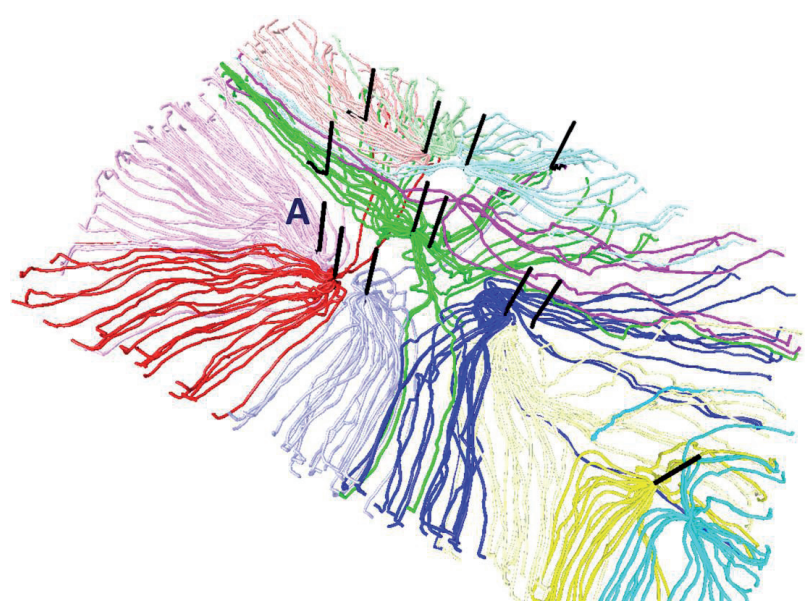

Figure 6

Streamline distribution for all wells at one time step during production of the Nelson field. Only a sample of streamlines is shown to enhance visualization. The streamlines are colour coded according to the well of origin. 


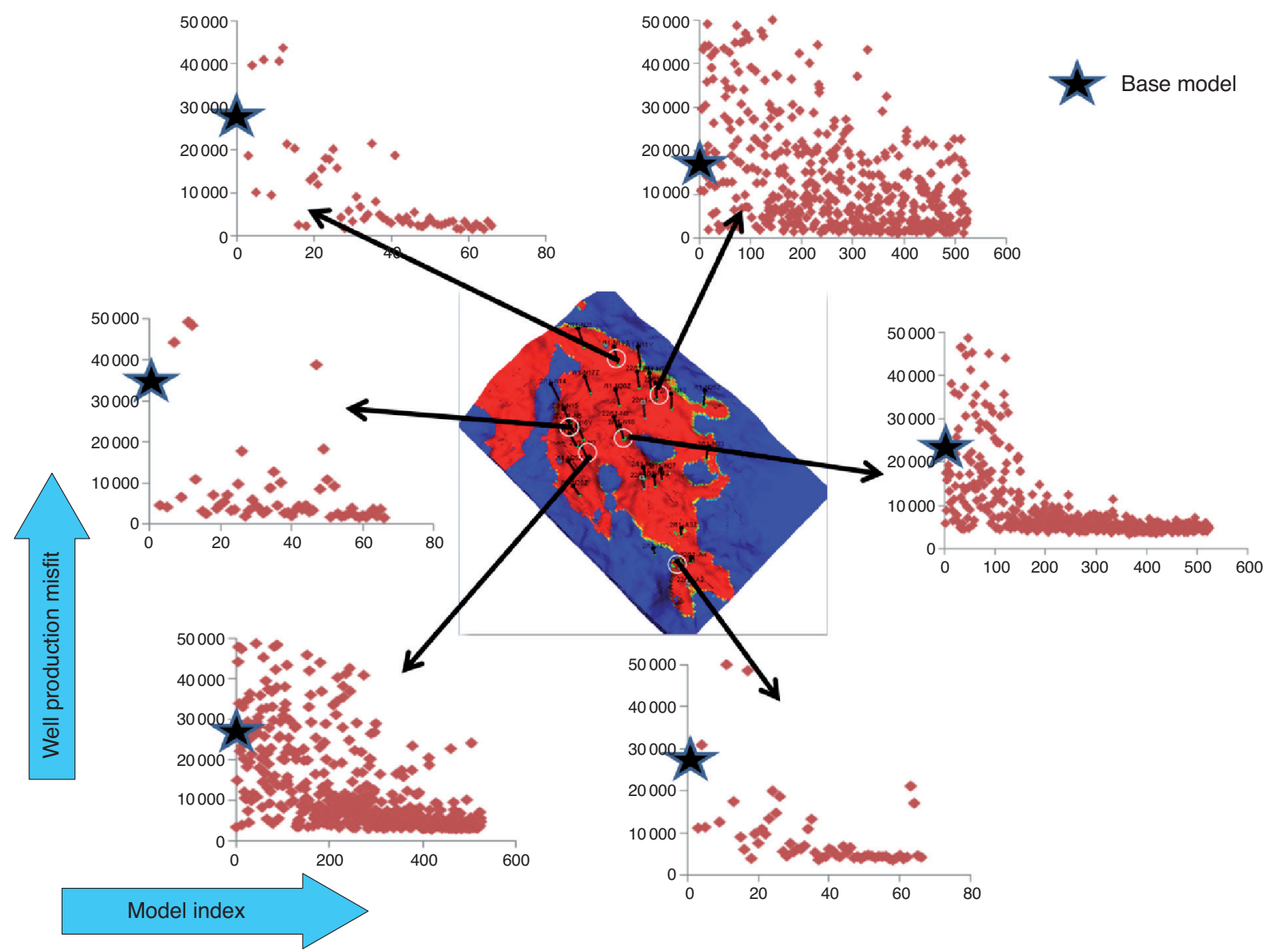

Figure 7

Well water production misfit versus model index for 6 wells in different part of the reservoir, the blue star shows the misfit value of base model.

Typically, we increase the ratio of horizontal permeability versus vertical permeability from 10 to around 13 and this increase leads to more edge drive from the aquifer and less bottom drive. This is better seen in Figure 10.

In Figure 11, we can see the total misfit value of the base model and the 10 best models history matching (Fig. 11a) and forecast periods along with the percentage reduction (Fig. 11b). The history match misfit is around $70 \%$ lower for all models but for forecasting the reduction varies from 10 to 40 percent. Overall, model 9 is the best model and we plot the oil rate and water cut for 4 wells in different locations to see the change of production profile (Fig. 12). The forecast period also has a good match.

\subsection{Sensitivity of Pilot Point Locations}

In order to understand better the importance of correctly locating the pilot points in the reservoir by streamlines, we perform a sensitivity analysis. For each well, the streamline approach is used to identify a preferential location of the pilot point groups and the modified area is offset from the well. In general, approximately three-quarters of the area around each well is unchanged. We now consider the relative impact of changing those other three quarters, each as a pilot point region. We do this one region at a time and for multiple regions including the region obtained via streamlines. We identify the area obtained by streamlines in Figure 13 as the black box and the three remaining regions using the coloured arrows with labels A-C for each well. These new pilot point locations are treated in the same way as the streamline guided area such that the dimensionality of the sub-problem is the same.

We choose the three wells in Figure 13 due to their respective fluid behavior which results from connectivity with the aquifer. For Well 1, regions $1 \mathrm{~B}$ and $1 \mathrm{C}$ are located between Well 1 and another well and changes there will 

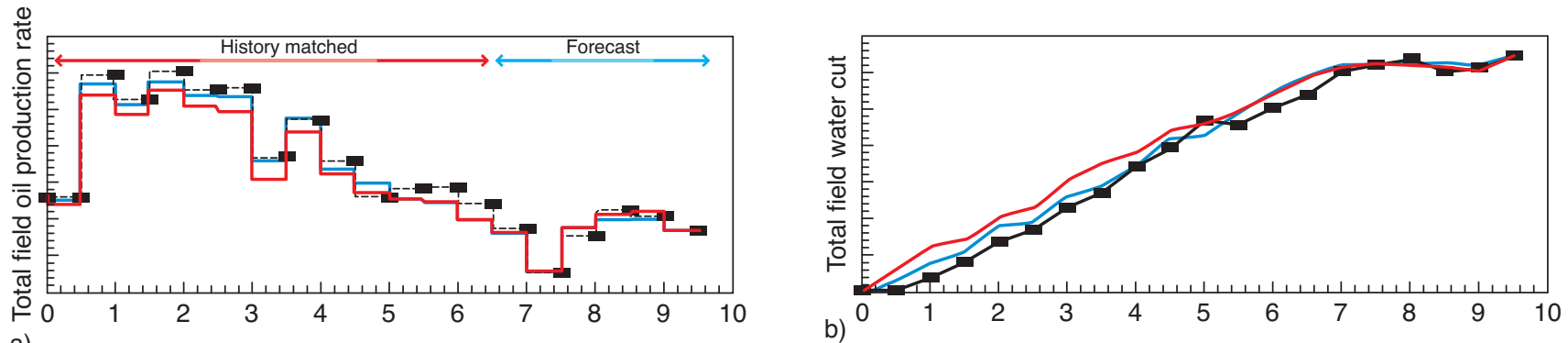

a)

Figure 8

a) Total field oil production rates and b) water cut for the best model compared to historical data and the base case model.

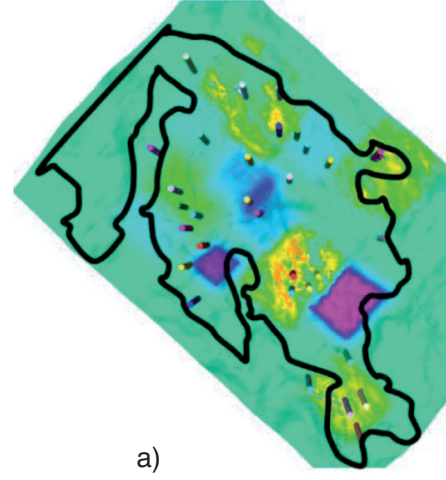

Figure 9

Ratio of best to base case model parameters for a) net:gross, b) horizontal permeability and c) vertical permeability.

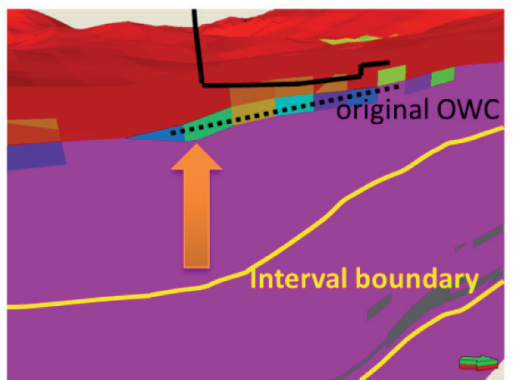

a)

1 Feb 1996

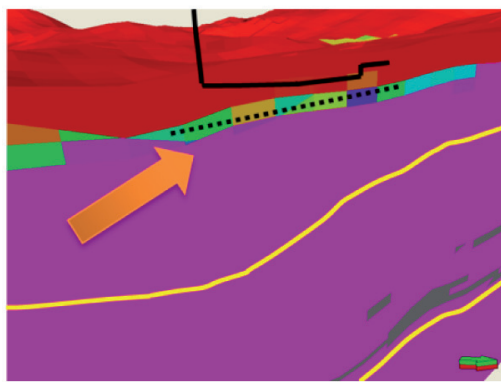

d)

Figure 10

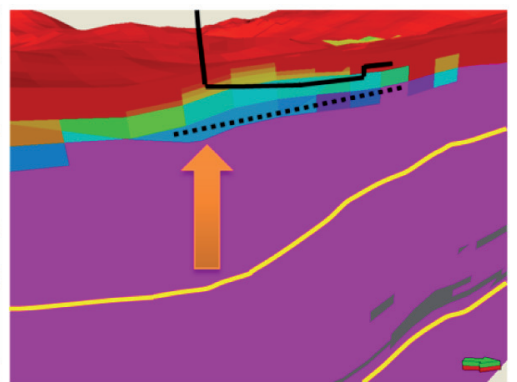

b)

1 Feb 1997

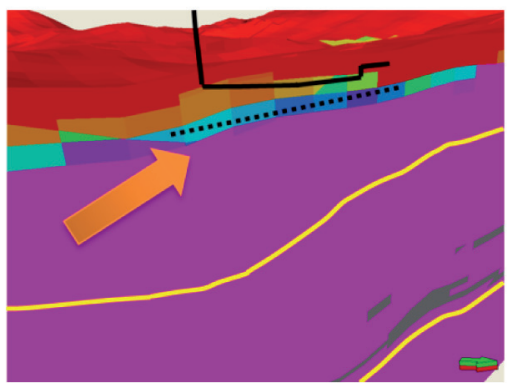

e)

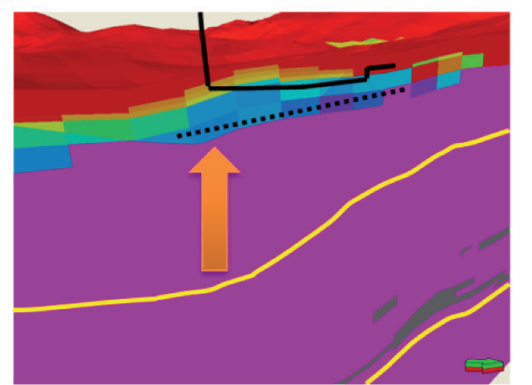

c)

1 Feb 1999

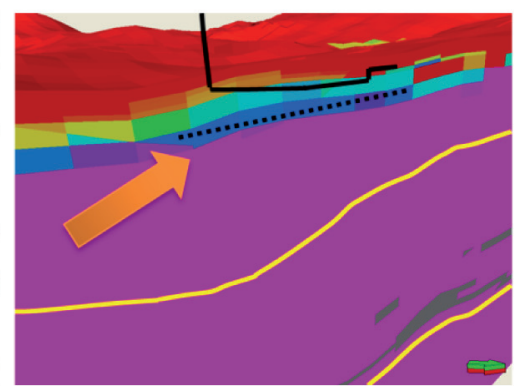

f)
So

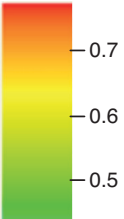

0.4

0.3

0.2

$-0.1$

Cross section of water movement near a well for the base model (a to c) and one of best models after history matching (d to f) at three time steps. The arrow shows the water discplacement from the aquifer toward the well. Because this is a 3D view the water oil contact does not look horizontal. 

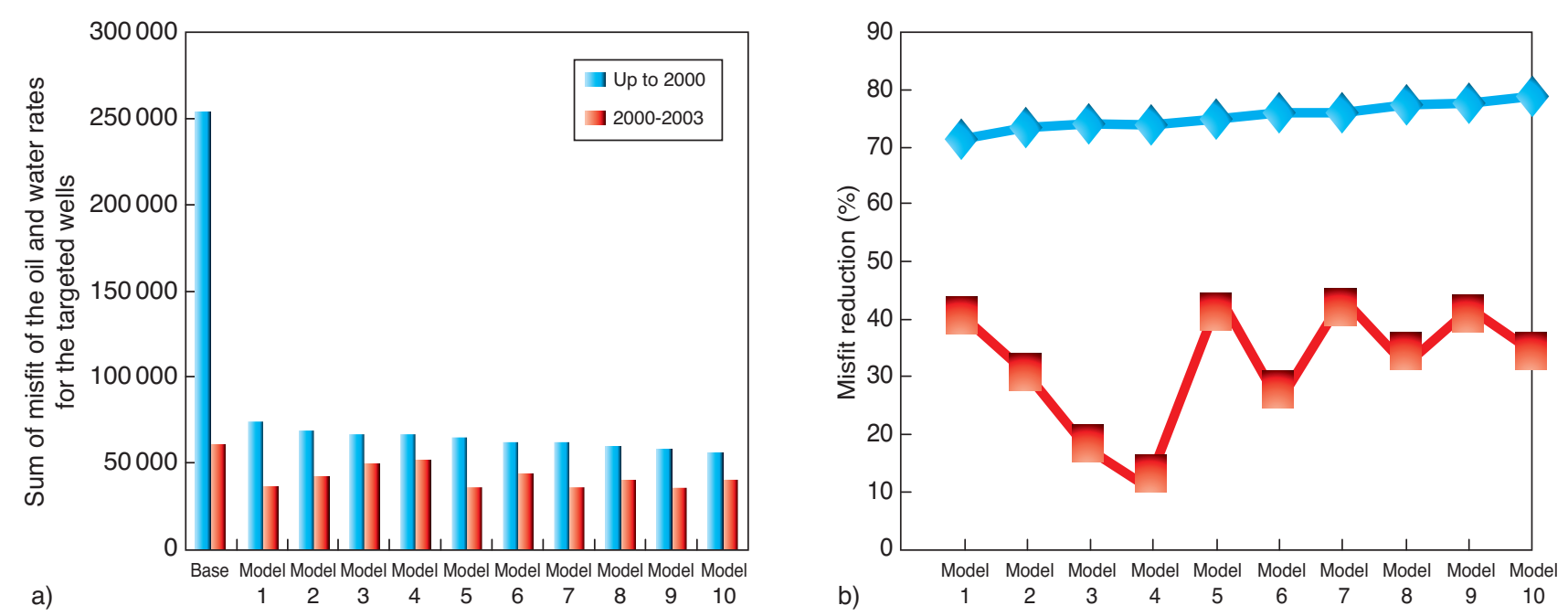

Figure 11

Oil and water misfit reduction for the best 10 models in history and forecast periods.

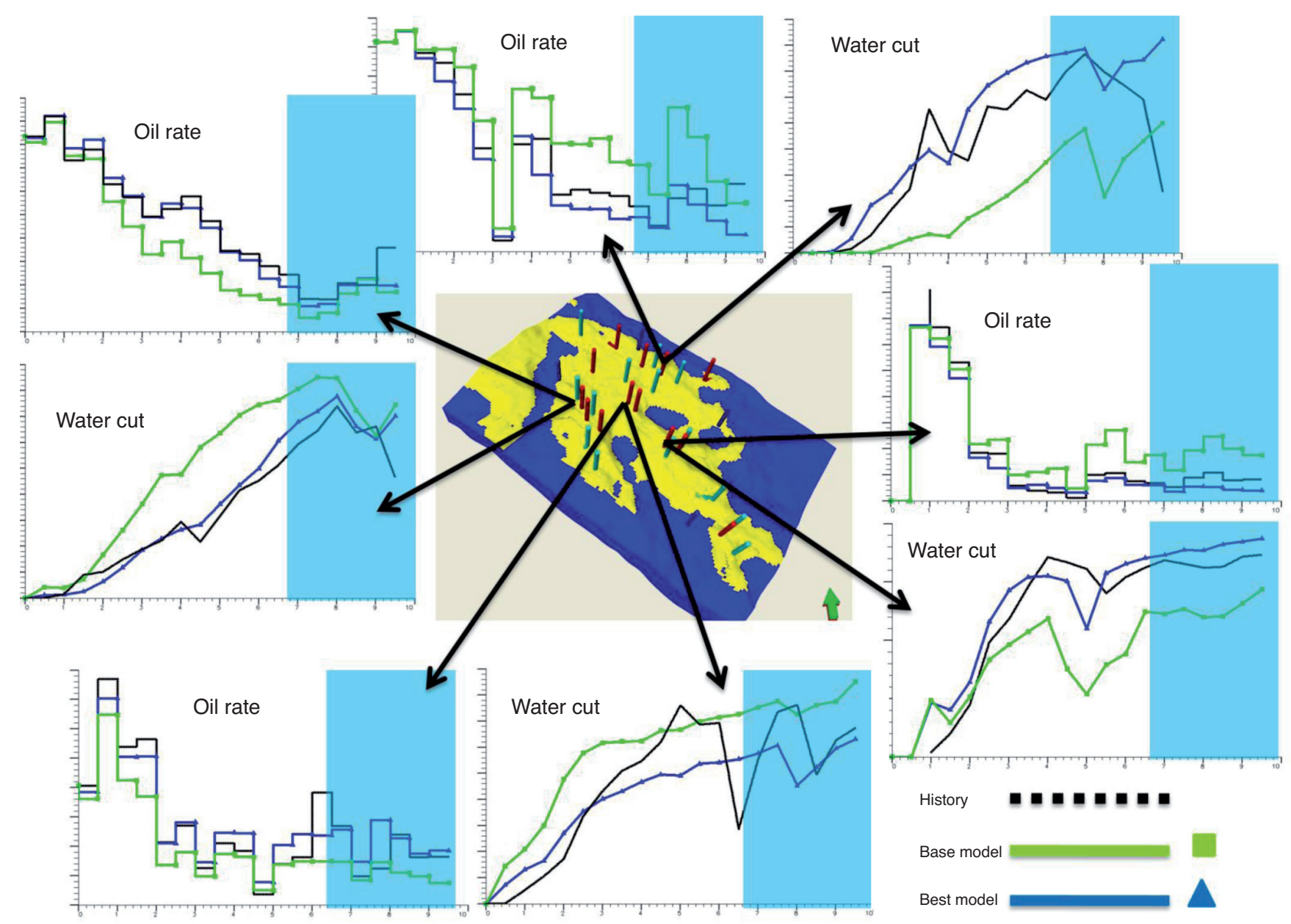

Figure 12

Oil rate and water cut of 4 different wells in history and forecast (light blue) period. 


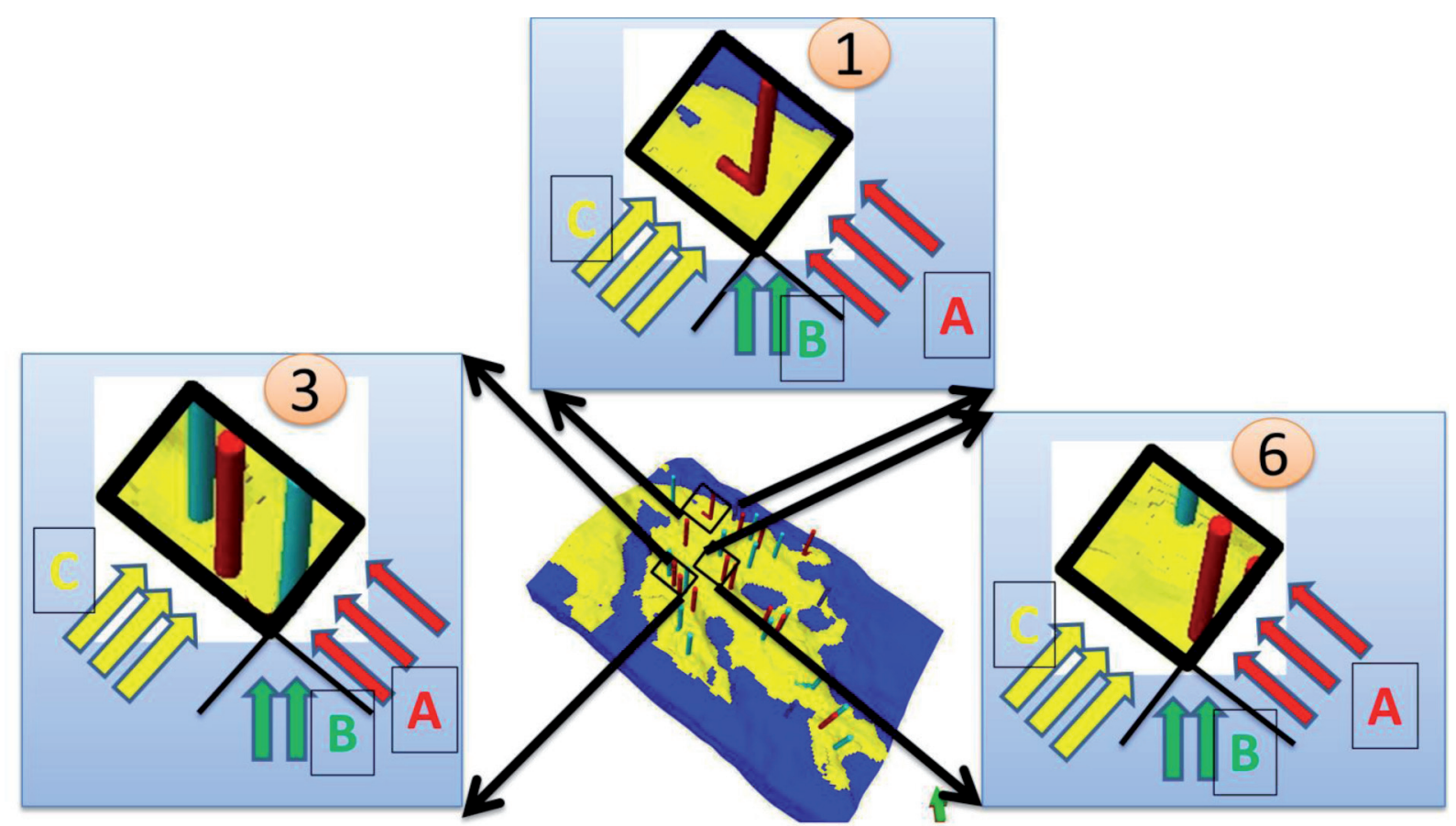

Figure 13

Three wells and associated regions in the reservoir chosen for a sensitivity study of the streamline guided approach. The well numbers above correspond to the wells identified in Figures 4 and 15. Black boxes indicate regions suggested for updating by streamlines while A, B and C regions are alternatives considered for each of the three wells.

affect the water displacement from the aquifer. The streamline guided area for Well 3 is also in the edge of the reservoir with an injector nearby. There are two other producers very close and within the box. Although, we target a particular well to improve the match, we do not want to degrade the match of other wells in the process. Area 3 is located at the centre of the reservoir and there is no injector close to this well. In contrast to Wells 1 and 3, this well is completed in both geological intervals whose different properties add complexity. Three areas for pilot points are chosen in both intervals around this well and each could be representative of different water displacement toward this producer.

Both Well 1 and Well 3 history matching cases are three dimensional for the original streamline guided region and so for $\mathrm{A}, \mathrm{B}$ and $\mathrm{C}$ the same dimensionality is considered. We change each of $\mathrm{A}, \mathrm{B}$ and $\mathrm{C}$ properties on their own but also perform history matching modifying them with the region identified from streamlines so that we have six dimensional problems. We combe the two areas (or sets of pilot points) because we want to investigate whether or not there is a local interaction and to determine if changes are spread more widely round the well. For Well 6, however, because the pilot point locations are in two intervals the history matching cases are 6 dimensional. Therefore, we only run history matching individually in $6 \mathrm{~A}, 6 \mathrm{~B}$ and $6 \mathrm{C}$.
Figure 14 compares the misfit change when updating the alternative areas A, B or C separately compared to the streamline guided case. The streamline guided result is clearly the best option in all cases. There is some improvement to the target wells when changing the properties in the other areas. In fact, we get different results with less change in the streamline guided region when combined with $\mathrm{A}, \mathrm{B}$ or $\mathrm{C}$. However, we also found that the misfit of non-targetted wells deteriorated so if these were included in the misfit then very little change to the alternative areas occurs. This sensitivity study for the three wells shows that regardless of the complexity of the history matching problem by the combination of well location and interaction with other parts of reservoir, the optimum location of pilot points around these wells are based on the streamline guide approach.

\section{WELL VICINITY VERSUS STREAMLINE GUIDED APPROACH}

The alternative to using streamlines to select locations to change is probably the most used and focuses on the area in the vicinity of each well (Solorzano et al., 1973), as in Figure 15. In this case, the reservoir properties in all directions but close to the well are considered to have equal 


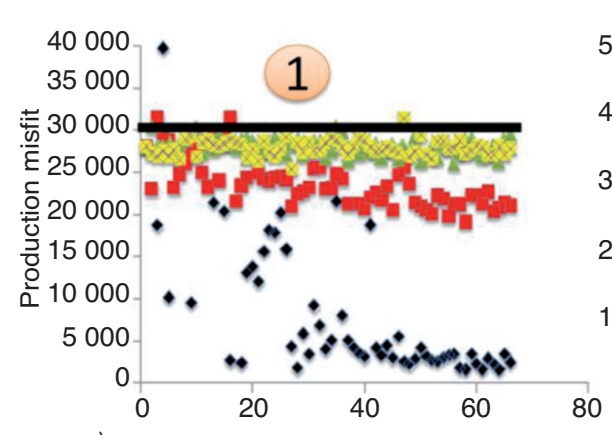

a)

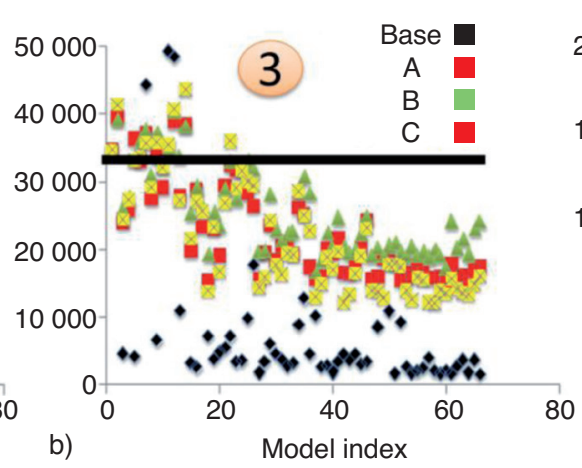

b)

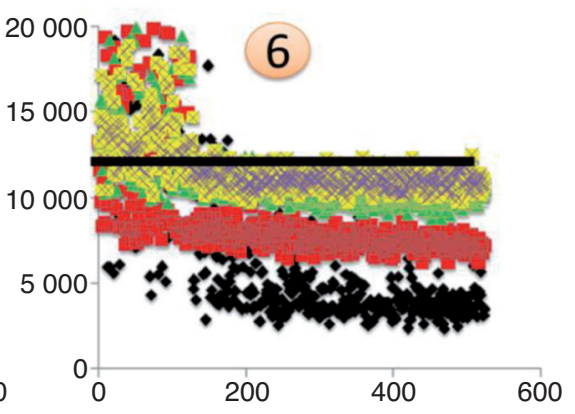

Figure 14

Reduction of production misfit value using new location of pilot point groups compared to the original case using the streamline guided approach for the three regions in Figure 13: a) 1, b) 3 and c) 6. The colour coding is consistent with the colours of each of the sub-regions A-C in Figure 13.

importance on updating. The modified regions now have the wells located in their middle. As above, we use the local multi-variable scheme for each well to improve the same reservoir properties. The only difference here is the location of the pilot points. Again, we consider the reduction in the production misfit for the same wells.

For 7 wells in the reservoir, we plot the reduction of oil and water production misfit in Figure 16 and compare the results to the reduction for the streamline guided approach. We also compare the trend of the reduction compared to the original value of misfit for base reservoir model. The first observation from Figure 16 is that for all of these areas we get a reasonable decrease in misfit values for the well vicinity approach but the streamline guided approach is about twice as good.

After combining the best models in each region, we generate the 10 best reservoir models for the both streamline driven and well vicinity approaches. We calculate the total production misfit of oil and water for the wells that we used in history matching. Figure 17 shows the production misfit for the base reservoir model and for the best 10 models for the streamline guided and well vicinity approaches. Overall the well vicinity approach is fifty percent worse than the streamline guided method (Fig. 17a). Moreover, the forecast is worse if the streamline guide is not used (Fig. 17b). In order to illustrate the improvement offered by using streamlines, we plot the oil and water rates of the wells in different location of the reservoir for the history matching and forecast periods (Fig. 18).

One important issue in history matching is the correlation of forecast versus the history matching misfit. We need to know whether a good history matching model also gives a good forecast. For this purpose, we plot the misfit improvement in forecast versus history matching for the best 10 models chosen after matching for both streamline and well vicinity cases in Figure 19. There are two main observations about this figure. Firstly, there is a broad correlation that better

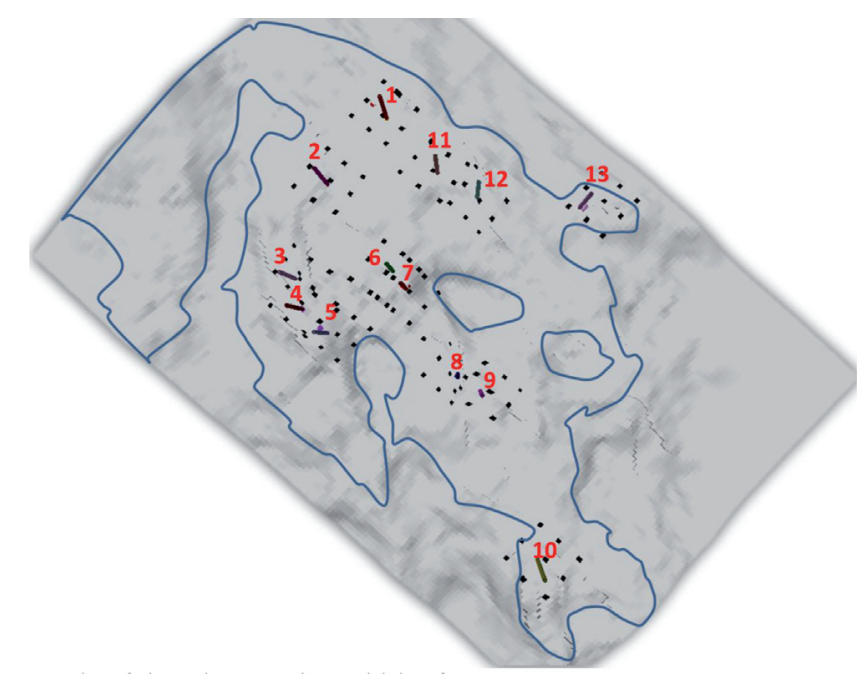

Figure 15

Location of pilot point groups in the vicinity of each well.

history matching models forecast better. The streamline guided models consistently match history and forecasts better than those obtained with the well vicinity approach. An important consideration for the history matching process is how we update the reservoir: are the new properties consistent with our prior geological knowledge? In Figure 20, we can see the ratio of the best model variables compated to the base case for the case where pilot points were placed in the well vicinity. These are qualitatively similar to the results for the streamline guided study (Fig. 9). On balance, there are increases to the variables across the model. These changes are very smooth in most of the areas for streamline cases but the well vicinity case results in more localized changes which may be less geologically valid.

Focusing on the area indicated by the arrows in Figure 20a, the well vicinity and streamline guided updates are quite different. 


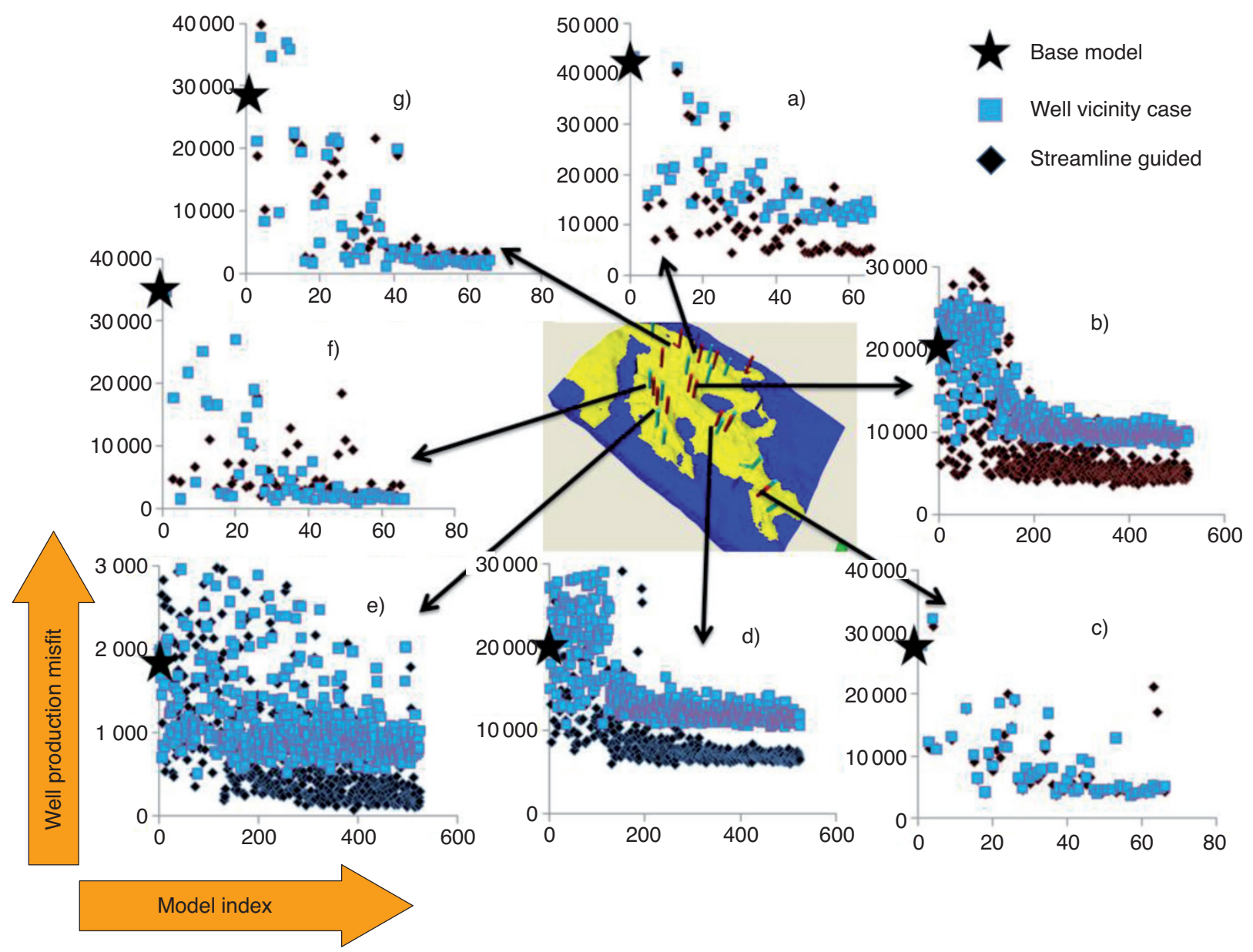

Figure 16

Well production misfit through history matching for well vicinity and streamline case in different locations in the reservoir.
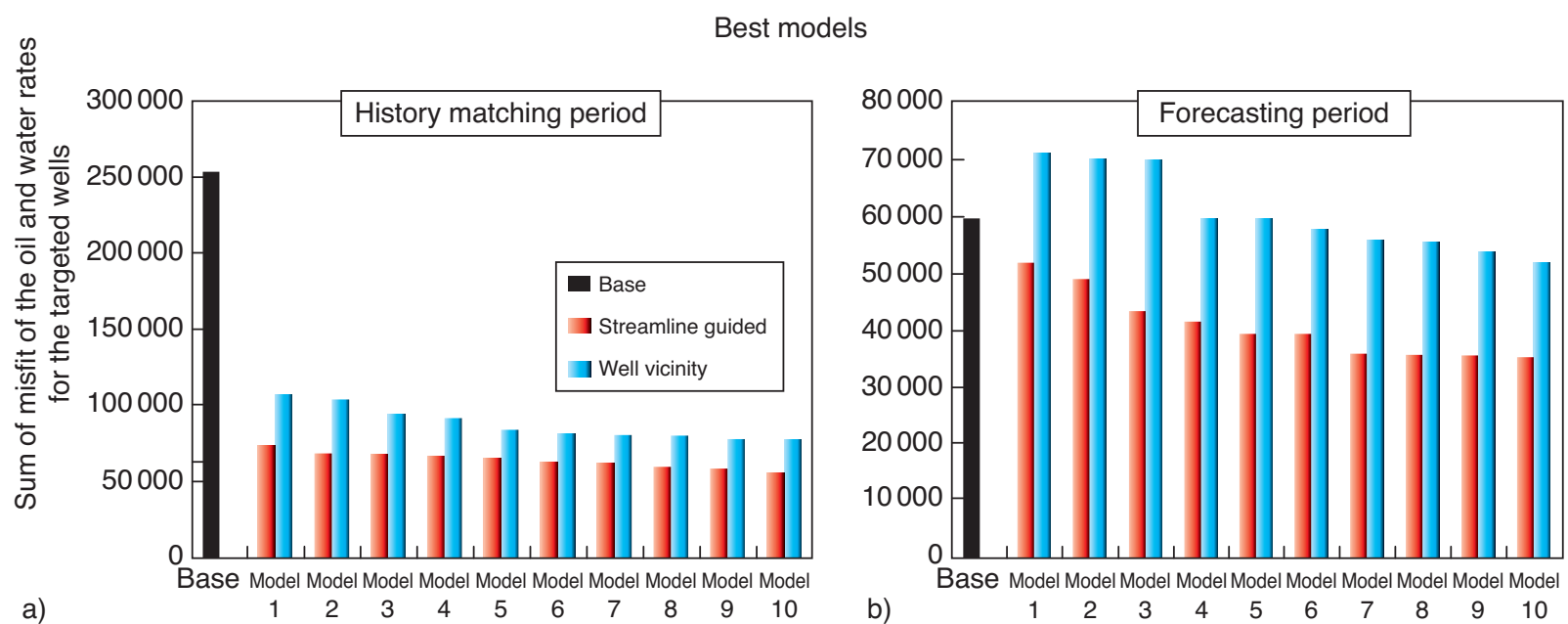

Figure 17

Total production misfit value of the wells used in: a) history matching in matching period and b) forecast period. 


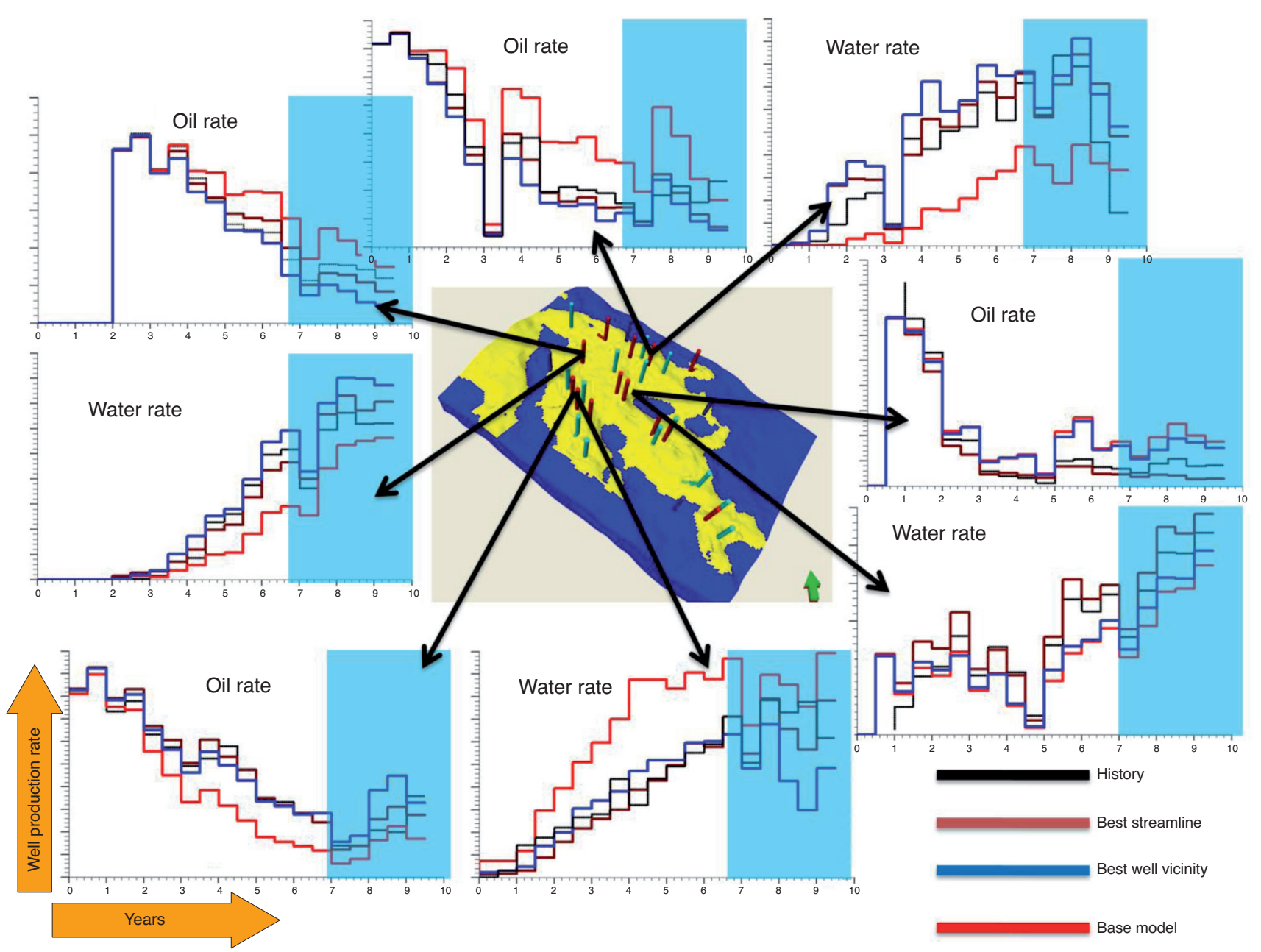

Figure 18

Oil and water production rates for the best model of well vicinity and streamline case in different location of the reservoir for history matching and forecast (light blue).

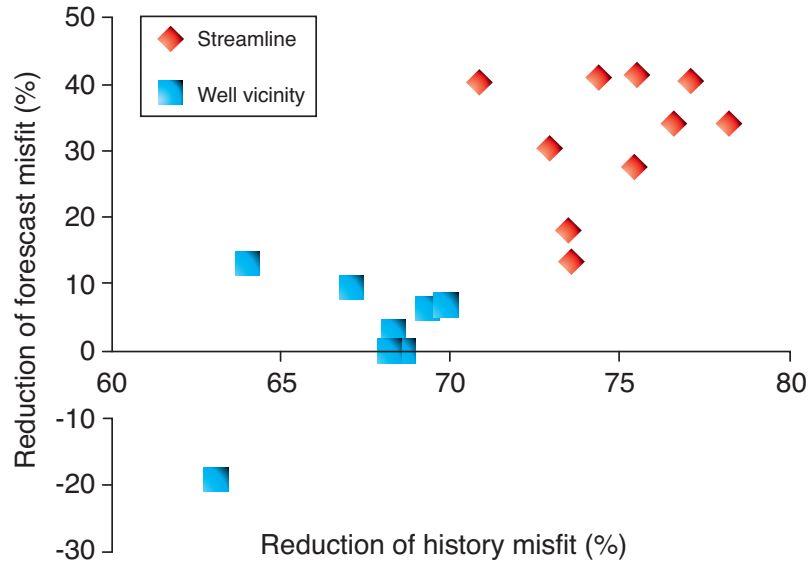

Figure 19

Cross plot of the misfit reductions in the history matching and forecast periods for best 10 models of the well vicinity and streamline guided cases.
This area which belongs to a production well that is supported mainly by a water injector nearby. In the streamline guided case, we observe increasing horizontal permeability which means that we try to increase the movement of water from injector to producer. On the other hand, updating the reservoir in the well vicinity results in increases to the net:gross only which means increasing the volume of oil close to the well and which delays breakthrough for the well by slowing down the front propagation. The history matching result in Figure 18 shows that updating the reservoir guided by streamlines can better match this well and we get a better forecast. We can conclude that the streamline guided method is more accurate at selecting areas and then finding appropriate changes to make.

In the area indicated by arrow 2 in Figure 20a, there is a production well which is supported by the aquifer below the reservoir. In the streamline guided case, by increasing the 


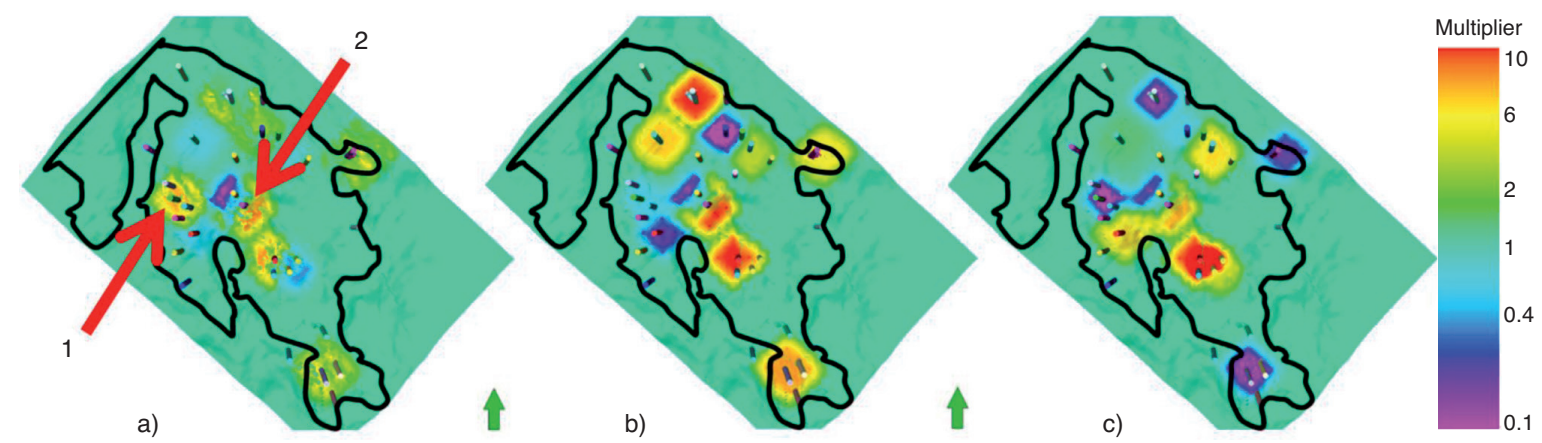

Figure 20

Ratio of best well vicinity derived case to the base case model parameters for: a) net:gross, b) horizontal permeability and c) vertical permeability.
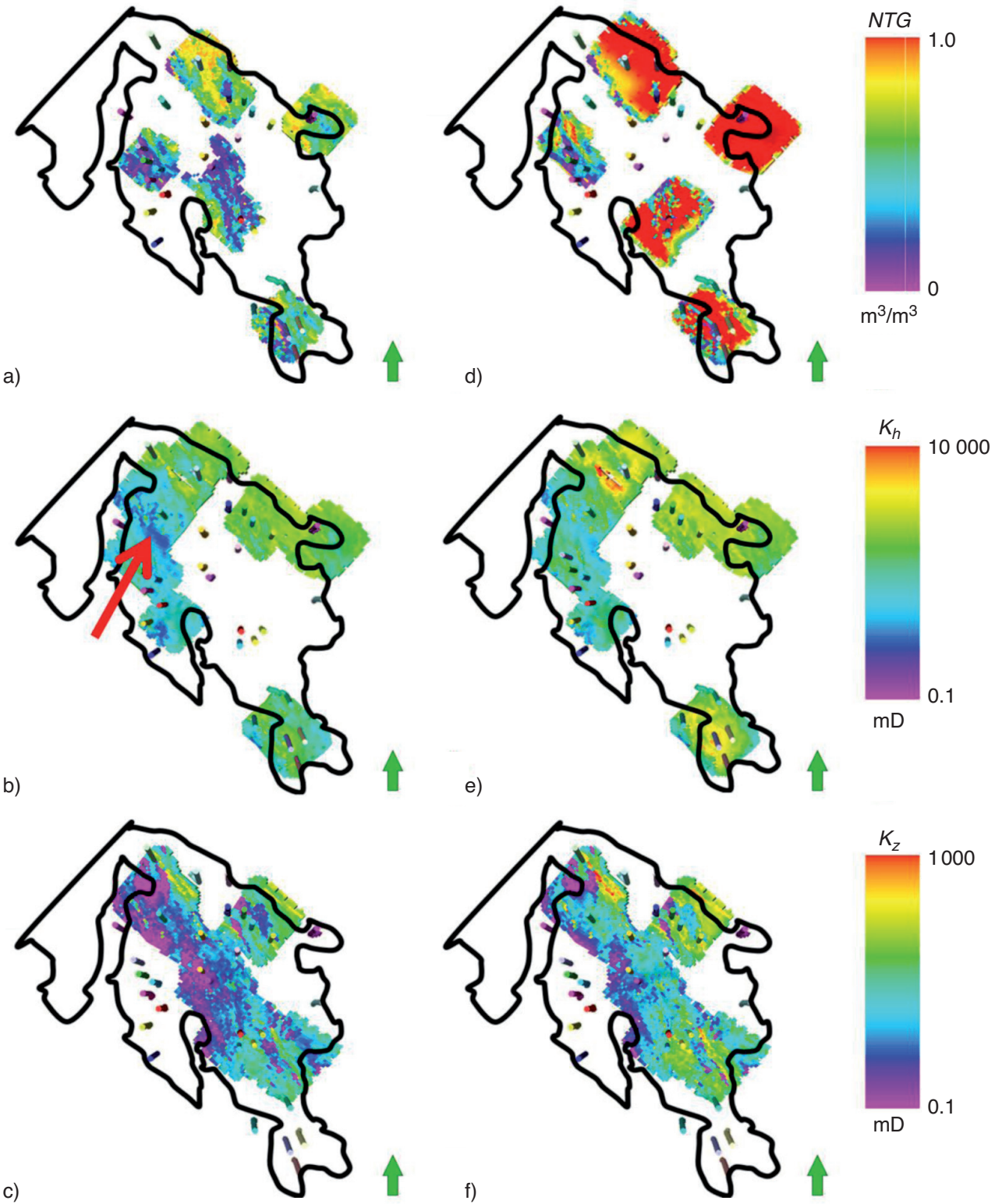

Figure 21

Properties for those cells where increases were applied as a result of history matching showing: a) net:gross, b) horizontal permeability, c) vertical permeability for the base case model, d) net:gross, e) horizontal permeability and f) vertical permeability for the best history matched model using streamlines. 
a)
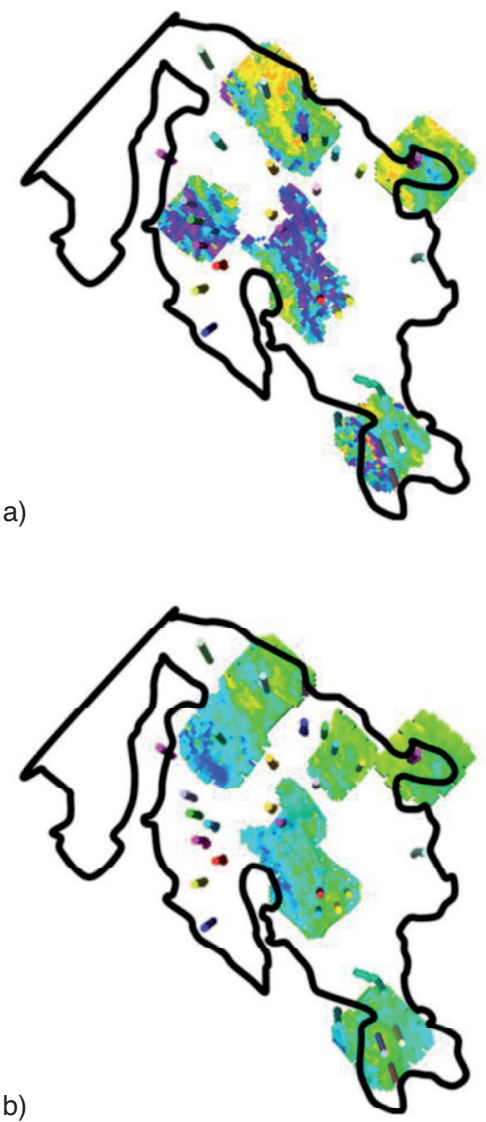

b)

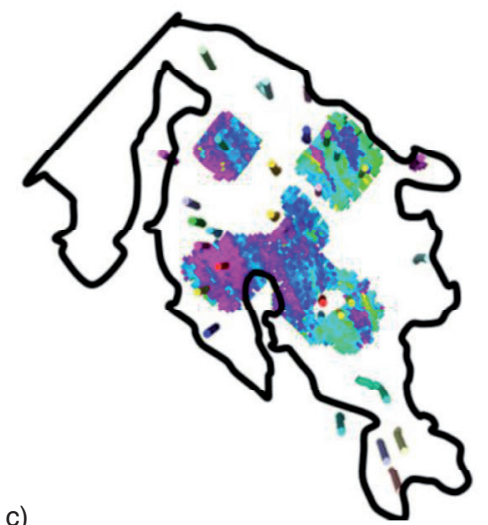

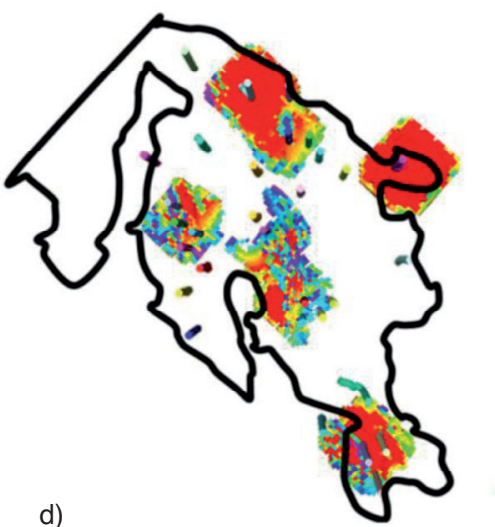

d)

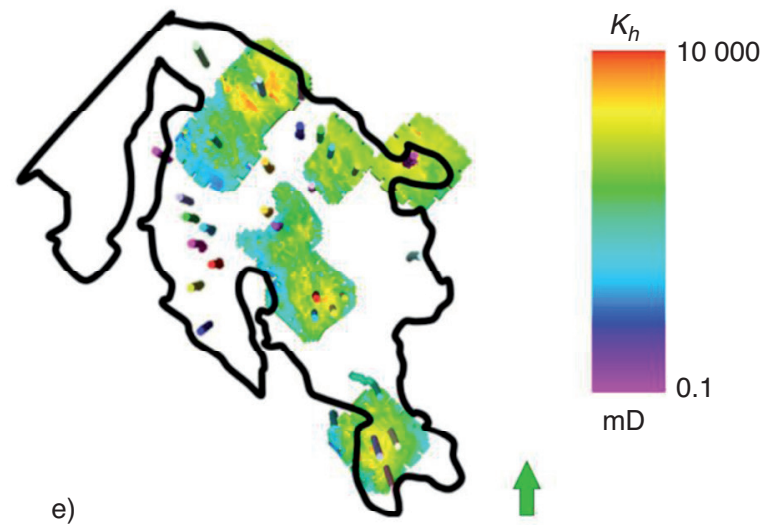

e)

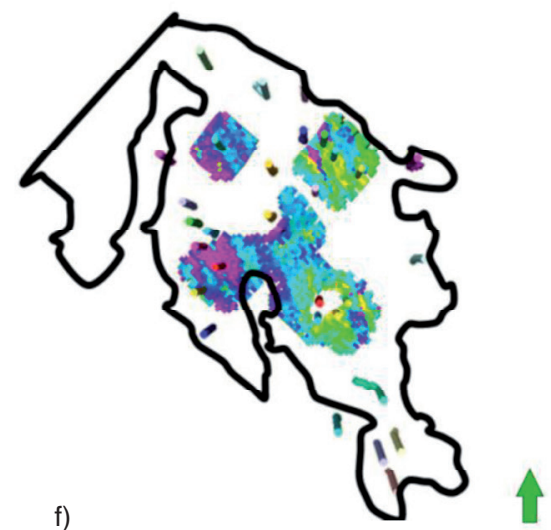

NTG

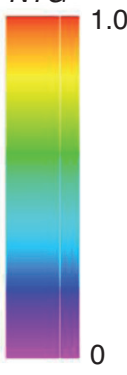

$\mathrm{m}^{3} / \mathrm{m}^{3}$
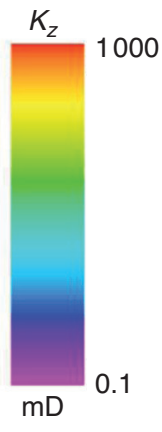

Figure 22

Properties for those cells where increases were applied as a result of history matching showing a) net:gross, b) horizontal permeability and c) vertical permeability for the base case model and d) net:gross, e) horizontal permeability and f) vertical permeability for the best history matched model locating pilot points in the well vicinity.

vertical permeability of the model and decreasing horizontal permeability and net:gross, we effectively modify the distribution of shale in this part of the field so that there is more connectivity to the aquifer. In contrast, the well vicinity case we increase all three variables near the well but net:gross and horizontal permeability are slightly decreased to the north west. Figure 18 shows the production data for this well and the match in the well vicinity case is not good. This in itself indicates that while we try to increase the water rate, the parameterization scheme doesn't allow it. 


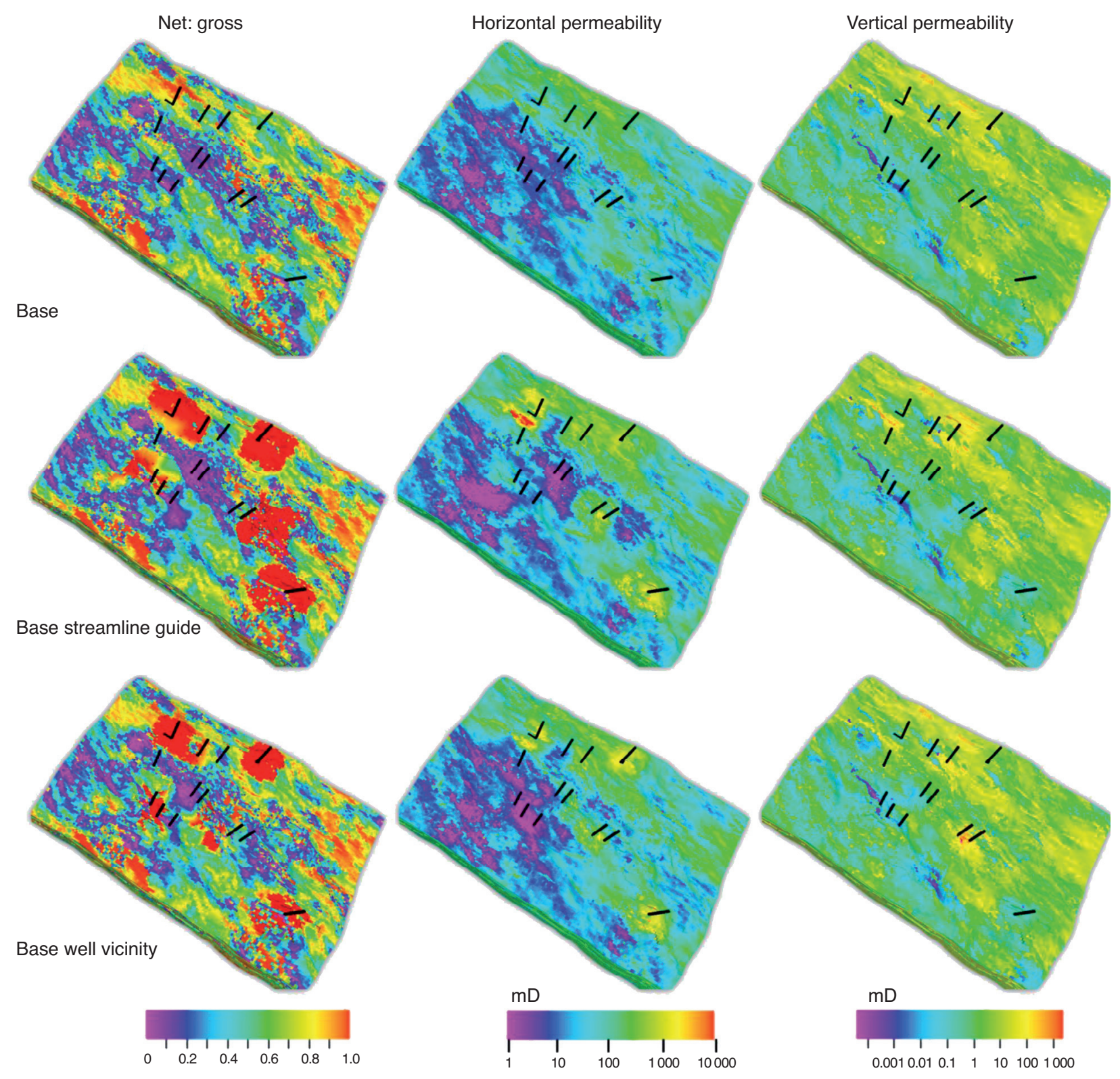

Figure 23

The map of net:gross, horizontal and vertical permeability for base case model, best model using streamline guide concept and the best using well vicinity concept.

Apart from analysing the ratio of variables (Fig. 9 and 20), we also consider the new value of the variables following history matching. On balance, the properties are increased and we focus on the cells with large changes in Figure 21 and Figure 22 by filtering out the cells in the reservoir where variables not changed. We apply the same filtering for the base model therefore for each parameter we can compare the value of each parameter for the cells with large change in Figures 9 and 20.
In Figure 21, we can see that for the streamline guided case the underlying geological heterogeneity distribution is retained, albeit modified. In the net:gross distribution, for example in Figure 21a, we model organized connected shales. Even though net:gross is increased through history matching, the organization remains afterwards. For the well vicinity case, however, we can say that we lose this geological feature from the model. For example in Figure $21 \mathrm{~b}$ for horizontal permeability, we obtain a region with relatively 
lower values of permeability compared to the rest of the model. After history matching in Figure 21e, we see that this heterogeneity distribution is retained and after increasing parameter values, we have relatively lower values of permeability. In the channel, we increase permeability but the channel shape remains. Again, we can see that in streamline guided case we change the parameters more smoothly, areally, compare to the well vicinity which is more local around the well. Also, we can see that for some cells in the reservoir we increase net:gross to unity thus increasing the sand content. Figure 23 shows the updated reservoir properties for best simulation models.

\section{DISCUSSION}

In this paper, we showed how we can identify the best regions in the reservoir for updating using streamlines as a guide. We found this method to be very useful in the Nelson field though there could be some fields where the approach requires more care in application. One case might be where we choose to update near a producer and then a new well is drilled during the history matching period. In this case, the density of streamlines will be changed because of the impact of the new well. We would therefore need to history match in stages, perhaps focusing on the initial well configuration and then making further modifications once the new well is in place.

As an extension to this, we may consider that instead of focusing on the time steps with high misfit only, we could give equal importance to each time step. Then, from the beginning for each time step, we could map the streamlines towards the production wells and add pilot points to control changes to these streamlines. We would update the reservoir parameters successively for each time step by carrying updates onwards in time. If the new model can match the production profile of the well we can continue with this model. Otherwise, we need to map the streamlines onto the new time step and by choosing new pilot point we can then update the reservoir through history matching.

Another case where the approach may require care is in a mature field with high well density. Finding the location to change may be problematic. On the one hand, this case may be easier to history match if the well separation is less than the correlation length of the permeability field. We propose that in such a case, smaller regions should be considered for updating (i.e. single pilot points with appropriate Kriging parameters, including the variogram range). Thus the dimensionality of the history matching problem will increase. An alternative inversion routine would be preferable and so a Genetic Algorithm may be more appropriate.

In this study, we introduced a parameterization and updating scheme for better history matching called local multi-variable and applied that for a history matching study of Nelson using a number of wells. The results confirmed the usefulness of this scheme and we improved the match of the wells and also the forecast for the following three years. Comparing to other work in this area for updating the reservoir our method is more applicable for big reservoirs because it reduces the number of unknowns, saving CPU time. In most of the approaches presented previously, the whole simulation model is chosen for updating which increased the CPU time drastically.

In order to investigate the optimum method of choosing the pilot point locations, we carried out a sensitivity study for three wells and we found that our streamline guided approach is optimal for choosing the where to update the reservoir model. Also, we compared the history matching result with a case which we put our pilot point in the vicinity of each well and we found that the streamline guided history matching is more applicable and useful for the Nelson.

\section{CONCLUSIONS}

We conclude the following from the work presented in this paper. The well vicinity approach for updating can be used to reduce the misfit in history matching but forecasts are not so good. Better results for history matching and forecasting is obtained by targeting specific regions of the reservoir and these can be identified using streamlines. Overall, we find that the better the match to history data the better the forecast indicating a distinct correlation. Geological concepts are better preserved using the streamline guide rather than the well vicinity approach as well. The streamline guided approach works very well in a local multi-variable method.

\section{ACKNOWLEDGMENTS}

We would like to thank the Nelson Field partners (Enterprise Oil Ltd., Esso Exploration and Production UK Ltd., ExxonMobil, Idemitsu E\&P UK Ltd., Premier Oil ONS Ltd., Shell $U K$ and Total E\&P UK) for providing the data and permission to publish the results. BP, ConocoPhilips, Shell and StatoilHydro are thanked for funding of this work. We thank Schlumberger Geoquest for use of their software. Malcolm Sambridge is thanked for use of the Neighbourhood Algorithm.

\section{REFERENCES}

Agarwal B., Blunt M.J. (2004) A Streamline-Based Method for Assisted History Matching Applied to an Arabian Gulf Field, SPE J. 9, 4, 437-449.

Baker R.O. (2001) Streamline Technology: Reservoir History Matching and Forecasting = Its Success, Limitations and Future, J. Can. Pet. Technol. 40, 4, 23-27.

Bissell R.C., Dubrule O., Lamy P., Swaby P., Lepine O. (1997) Combining Geostatistical Modelling with Gradient Information for History Matching: The Pilot Point Method, SPE Annual Technical Conference and Exhibition, San Antonio, Texas, 5-8 Oct., SPE Paper 38730-MS. 
Bissell R.C., Sharma Y., Killough J.E. (1994) History Matching Using the Method of Gradients: Two Case Studies, SPE Annual Technical Conference and Exhibition, 25-28 September, New Orleans, Louisiana, SPE Paper 28590-MS.

Caers J. (2003) History Matching under Training-Image Based Geological Model Constraints, SPE J. 7, 218-226.

Chavent G., Dupuy M., Lemonnier P. (1975) History Matching by Use of Optimal Theory, SPE J. 15, 1, 74-86.

Chen W.H., Gavalas G.R., Seinfeld J.H., Wasserman M.L. (1974) A New Algorithm for Automatic History Matching, SPE J. 14, 6, 593-608.

Cheng H., Wen X.-H., Milliken W.J., Datta-Gupta A. (2004) Field Experiences with Assisted and Automatic History Matching Using Streamline Models, SPE Annual Technical Conference and Exhibition, Houston, Texas, 26-29 Sept., SPE Paper 89857-MS.

De Marsily G.H., Levendan G., Boucher M., Fasanino G. (1984) Interpretation of Interface Test in a Well Field Using Geostatistical Techniques to Fit the Permeability Distributions in a Reservoir Model, in Geostatistics for natural resources characterization. Part 2, Verly G. et al. (eds), D. Reidel Pub Co, pp. 831-849.

Evensen G., Hove J., Meisingset H.C., Reiso E., Seim K.S., Espelid Y. (2007) Using the EnKF for Assisted History Matching of a North Sea Reservoir Model, SPE Reservoir Simulation Symposium, Houston, Texas, 26-28 Feb., SPE Paper 106184-MS.

Fenwick D., Thiele M., Agil M., Hussain A.P., Humam F., Caers J. (2005) Reconciling prior Geologic Information with Production Data using Streamlines: Application to a Giant Middle-Eastern Oil Field, SPE Annual Technical Conference Exhibition, Dallas, TX, 9-12 Oct., SPE Paper 95940-MS.

Gervais V., Roggero F. (2010) Integration of 4D Seismic Data in a History Matching Process using an Efficient Local Parameterization, J. Petrol. Sci. Eng. 73, 1-2, 86-98.

Gomez-Hernandez J.J., Sahuquillo A., Capilla J.E. (1997) Stochastic Simulation of Transmissivity Fields Conditional to both Transmissivity and Piezometric Data - 1.Theory, J. Hydrol. 203, 1-4, 162-174.

Haugen V., Natvik L.-J., Evensen G., Berg A., Flornes K., Naevdal G. (2006) History Matching Using the Ensemble Kalman Filter on a North Sea Field Case, SPE Annual Technical Conference and Exhibition, San Antonio, Texas, 24-27 Sept., SPE Paper 102430-MS.

Hoffman B., Caers J. (2005) Regional Probability Perturbations for History Matching, J. Petrol.Sci. Eng. 46, 53-71.

Hu L.Y. (2001) Gradual Deformation and Iterative Calibration of Sequential Simulations, Math. Geol. 33, 457-489.

Kazemi A., Stephen K.D. (2009) Automatic Seismic and Production History Matching in Nelson using Different Updating Scheme, 71st EAGE Conference and Exhibition, Amsterdam, the Netherlands, 8-11 June.

Kazemi A., Stephen K.D. (2012) Schemes for Automatic History Matching of Reservoir Modelling: A case of Nelson Oilfield in UK, Petrol. Exploration Dev. 39, 3, 349-361.

Le Ravalec-Dupin M. (2010) Pilot Block Method Methodology to Calibrate Stochastic Permeability Fields to Dynamic Data, Math. Geosci.42, 2, 165-185.
Le Ravalec-Dupin M., Fenwick D.A. (2002) A Combined Geostatistical and Streamline-based History Matching Procedure, SPE Annual Technical Conference and Exhibition, San Antonio, Texas, 29 Sept.-2 Oct., SPE Paper 77378-MS.

Maschio C., Schiozer D.J. (2005) Assisted History Matching Using Streamline Simulation, Petrol. Sci.Technol. 23, 7, 761-774.

Ouenes A., Brefort B., Meunier G., Dupere S. (1993) A New Algorithm for Automatic History Matching: Application of Simulated Annealing Method (SAM) to Reservoir Inverse Modeling, SPE Paper 26297-MS.

Portelland R.C.M., Prais F. (1999) Use of Automatic History Matching and Geostatistical Simulation to Improve Production Forecast, Latin American and Caribbean Petroleum Engineering Conference, Caracas, Venezuela, 21-23 April, SPE Paper 53976-MS. Roggero F. (1997) Direct Selection of Stochastic Model Realizations Constrained to Historical Data, SPE Annual Technical Conference and Exhibition, San Antonio, Texas, 5-8 Oct., SPE Paper 38731-MS. Sambridge M.S. (1999) Geophysical Inversion with a Neighbourhood Algorithm-I. Searching a Parameter Space, Geophys. J. Int. 138, 479-494.

Schlumberger Geoquest Manual (2011) Schlumberger.

Solorzano L.N., Arredondo S.E., Enrique S. (1973) Method for Automatic History Matching of Reservoir Simulation Models, Fall Meeting of the Society of Petroleum Engineers of AIME, Las Vegas, Nevada, 30 Sept.-3 Oct., SPE Paper 4594-MS.

Stephen K.D., Clark J.D., Gardiner A.R. (2001) Outcrop-based stochastic modelling of Turbidite Amalgamation and its effects on Hydrocarbon Recovery, Petrol. Geosci. 7, 163-172.

Stephen K.D., Shams A., Macbeth C. (2009) Faster Seismic History Matching in a United Kingdom Continental Shelf Reservoir, SPE Reserv. Eval. Eng. 12, 4, 586-594.

Stephen K.D., Soldo J., Macbeth C., Christie M.A. (2006) Multiple Model Seismic and Production History Matching: A Case Study, SPE J. 11, 4, 418-430.

Tan T.B. (1995) A Computationally Efficient Gauss-Newton Method for Automatic History Matching, SPE Reservoir Simulation Symposium, San Antonio, Texas, 12-15 Feb., SPE Paper 29100-MS. UK DTI (2009) www.og.decc.gov.uk/pprs/full_production.htm.

Walker G.J., Kromah M., Pham H., Adeyeye D.A., Winchester A. (2008) Assisted History Matching as a Useful Business Tool: An Example from Trinidad, SPE Indian Oil and Gas Technical Conference and Exhibition, Mumbai, India, 4-6 March, SPE Paper 113479-MS.

Watson A.T., Lee W.J. (1986) A New Algorithm for Automatic History Matching Production Data, SPE Unconventional Gas Technology Symposium, Louisville, Kentucky, 18-21 May, SPE Paper 15228-MS.

Zhang F., Skjervheim J.A., Reynolds A.C., Oliver D.S. (2005) Automatic History Matching in a Bayesian Framework, Example Applications, SPE Reserv. Eval. Eng. 8, 3, 214-223.

Final manuscript received in July 2012 Published online in May 2013

Copyright (C) 2013 IFP Energies nouvelles

Permission to make digital or hard copies of part or all of this work for personal or classroom use is granted without fee provided that copies are not made or distributed for profit or commercial advantage and that copies bear this notice and the full citation on the first page. Copyrights for components of this work owned by others than IFP Energies nouvelles must be honored. Abstracting with credit is permitted. To copy otherwise, to republish, to post on servers, or to redistribute to lists, requires prior specific permission and/or a fee: Request permission from Information Mission, IFP Energies nouvelles, fax. +33147527096 , or revueogst@ifpen.fr. 